\title{
An Investigation into the Causes of Pedestrians' Walking Difficulties in Cairo Streets
}

\author{
Joy Maged ${ }^{1}$, Rania Rushdy Moussa ${ }^{1}$, Usama Konbr ${ }^{2, *}$ \\ ${ }^{1}$ Department of Architecture, Faculty of Engineering, The British University in Egypt, El-Sherouk City, Cairo 11837, Egypt \\ ${ }^{2}$ Department of Architecture, Faculty of Engineering, Tanta University, Egypt \\ *Corresponding Authors: drusamakonbr@f-eng.tanta.edu.eg
}

Received July 24, 2021; Revised September 30, 2021; Accepted December 13, 2021

\section{Cite This Paper in the following Citation Styles}

(a): [1] Joy Maged, Rania Rushdy Moussa, Usama Konbr, "An Investigation into the Causes of Pedestrians' Walking Difficulties in Cairo Streets," Civil Engineering and Architecture, Vol. 10, No. 1, pp. 12 - 26, 2022. DOI: 10.13189/cea.2022.100102.

(b): Joy Maged, Rania Rushdy Moussa, Usama Konbr (2022). An Investigation into the Causes of Pedestrians' Walking Difficulties in Cairo Streets. Civil Engineering and Architecture, 10(1), 12 - 26. DOI: 10.13189/cea.2022.100102.

Copyright $\bigcirc 2022$ by authors, all rights reserved. Authors agree that this article remains permanently open access under the terms of the Creative Commons Attribution License 4.0 International License

\begin{abstract}
This paper intends to focus on Cairo streets from the pedestrian-use perspective. It aims to explore and examine the factors that make Cairo streets better places for walking. Moreover, it intends to contribute to the limited qualitative research on walkable streets and pedestrians' walking experience, specifically in Cairo. In addition, it provides a conceptual framework for understanding the walkability of streets and the experience of pedestrians, built on both empirical field study and prevailing theoretical models reviewed in the literature. To closely examine the factors that determine Cairo streets to be walkable and therefore pedestrian-friendly, the research investigates the status of two streets in Cairo as a case study. The case studies section investigated the street characteristics and the local pedestrians' needs and perceptions towards their walking experience in the streets. This study investigated the status of Cairo streets by recording the users' perceptions of different types to understand the causes of this problem. Moreover, to encourage the walking in Cairo streets and promote social activities, the study investigates two major streets in Cairo, "El-Korba and Al-Azhar," using qualitative research methods of participant interviews and observational surveys. Furthermore, it conducted a comparative study to examine the causes and proposals' solutions, down to the study's results.
\end{abstract}

Keywords Walking Difficulties, Walkability, Street Walking Quality, Pedestrian Mobility, Sidewalks, Streetscape, Social Satisfaction, Pedestrian safety, Cairo

\section{Introduction}

Recently, with much focus directed towards efficient transportation, the physical environment of many streets within cities has become unattractive for users [1].

Results of streets quality studies revealed that older adults' susceptibility to pedestrian incidents are difficulty walking, fear of falling, and crossing evaluation capability. It guides and prioritizes transportation authorities in their plans, policies, and programs towards improving the safety and mobility of pedestrians in general, and the older, especially [2].

The number of vehicles and motorists on the streets has increased significantly [1]. According to BBC News," Cars on England's roads increase by almost 600,000 per year [3] . The data can be recurring frequently across different parts of the world. Streets are designed to help people move from one place to another, whether by motors, animal transportation, and the most basic thing is walking. It should make transportation easier [4]. Furthermore, pedestrians have a designated area in the streets to help accommodate them and keep them safe from fast-moving objects such as cars.

Moreover, sidewalks and pavements are added to the sides of streets to maintain street balance and prevent chaos [5]. However, pedestrians in Cairo have walking difficulties due to many reasons for this problem. Therefore, we need to address, analyze, and conclude those difficulties.

This study explores the obstacles in Cairo streets, as streets may be classified as an urban element, which is a 
public space accessible to citizens. It is occupying much of our cities' surface area. Hence, the study is interested in how people inhabit and behave within this public space, especially, it is noticed that citizens users are attracted to shopping in shops and malls and restaurants, sitting at the edges or occupying the streets daily for traveling from one area of the city to another. Meanwhile, these streets do not meet the suitable interest, causing the absence of hospitable streets and spaces for pedestrians and emerging many walking difficulties [6]. This is the gap which this study attempts to bridge.

\section{Literature Review}

This study addresses the streets of Cairo through two streetscape elements, which are the sidewalks and the side corners, as follows:

Planners should examine streets' form, physical comfort, appearance, and character, determining if the streets meet the comfort standards [1]. Many studies addressed Egyptian streets in various themes and details to facilitate users' walkability, adopting some trends in urban design as environmental aspects in sustainable hardscaping $[7,8,31]$. For the last decades, the great growing population in Egypt in general and Cairo has resulted in an accumulation observed in the number of citizens and cars on very congested streets $[9,10]$. Some planners directed the gap solution in the current century towards framing its Cycling to decrease the congestion of the streets [11].

Recently, some trends pointed to the variations in walking accessibility joining it with some walking needs, as attractiveness, comfort, safety, and ease-to-walk [12], and how each urban design factor affects walking accessibility. Planners are busy searching urban factors related to attractiveness, removing difficulties, and achieving comfort, providing the most significant variations in walking accessibility [12]. Sustainable mobility paradigms as a trend attracted researchers to address walking accessibility. However, it paid little attention to determining which factors influence walking accessibility and Pedestrian Mobility [12].

Some planners went further, considering Street Walking Quality with pleasure is one of the city's basic rights [13]. Planners consider walking an important transport option regarding the older population, contributing to physical activity and individual quality of life. Therefore, it is significant to decrease driving speeds and care about safety and congestion [14].

The defined gaps in walking difficulties were linked to the key factors for selecting the walking routes are linked to attractiveness elements as green areas, amenities, tourist attractions, etc. On the other hand, those issues are linked to accessibility as obstacles, pavements, sidewalks width, street corners. Even transportation experts promote walking for transportation, considering it a promising strategy to address the traffic bottlenecks and environmental pollution and provide health benefits to pedestrians [15]. However, if the walking purpose is shopping, selecting streets represents a critical factor [15]. The ability to walk and active travel is becoming increasingly clear, so researchers need to investigate pedestrians' safety, walking difficulties in Cairo Streets, especially for the older because they are the most vulnerable [2].

\section{Methodology}

The study carried out information gathering about different mobility habits in Cairo streets. It focused on pedestrian mobility and the respondents' perceptions of issues related to mobility on foot. Moreover, it used comparative and qualitative methods considering different cases, where the opinion of pedestrians regarding the status of the street through the interviews and surveys to deduct and extract the real factors that influenced their walking experiences. The study chose two case studies in two different areas to become the study area of their research. These two case studies areas were chosen because they are well-known streets, and their pedestrians' number is very high. The study used the qualitative method to collect information needed to analyze, compare, and explore the real causes of this problem.

Moreover, this type of research identifies different opinions of pedestrians; thus, a clear analysis would be available as the reasons behind this issue would be shown. This is done to check if different pedestrians of different ages, backgrounds, and circumstances also agree with those different causes that affect walking in the streets of Cairo. Moreover, this research is used to take into consideration the people who might be suffering from this difficulty as they use walking as their main transportation or day to day trips and a place where the street contains residential buildings, office workers, shop users, and different types of day-to-day activities to get the most variety of pedestrians.

The research thus relied firstly on the inductive method and then on the field survey using site-seeing visits, interviews, and questionnaires for information gathering. Consequently, the analytical approach used the deductive method to qualitative and quantitative data processing.

\section{Monitoring the Condition of the Cairo Streets}

\subsection{The Status of the Sidewalks}

Many reasons force pedestrians to be unable to use the streets of Cairo, as they are not friendly to use. Usually, they are seen walking on both sidewalks of the streets 
mixed with cars. This increases the safety risks for pedestrians as they can be exposed to accidents [16].

\subsubsection{The general condition of the sidewalks}

In many cases, the condition of Cairo sidewalks is not good enough for a pedestrian to use, as shown in Figure 1, which is due to the lack of supervision or maintenance [17].

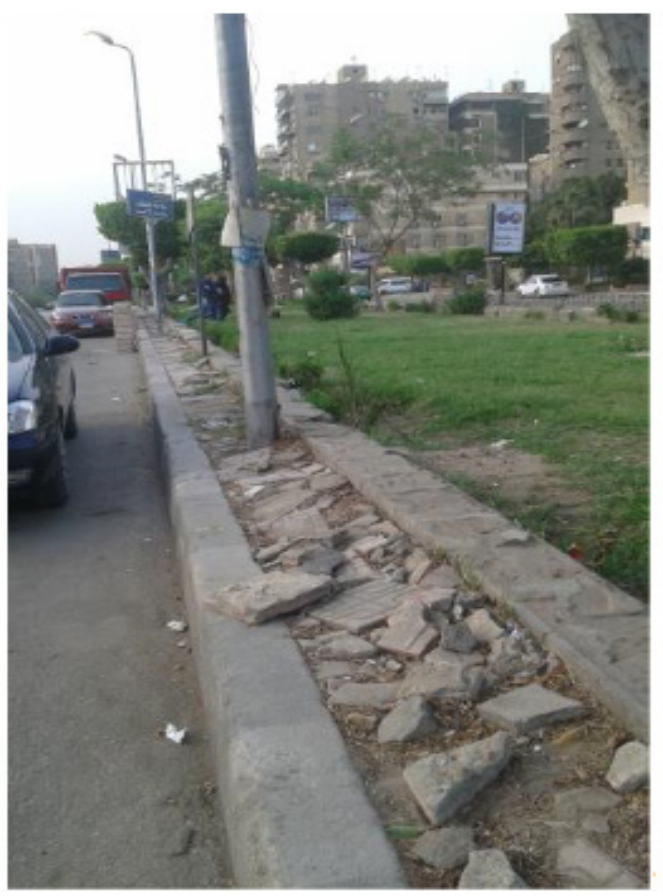

This problem forces pedestrians to walk on the streets with cars which causes safety risks on pedestrians and walkability difficulties, as shown in Figure 2, which may cause several injuries affecting people on many levels. In this regard, statistics showed that road injuries in 2012 reached up to 21,620 injuries, representing a significant number [18], causing a reason to keep the research in that point.

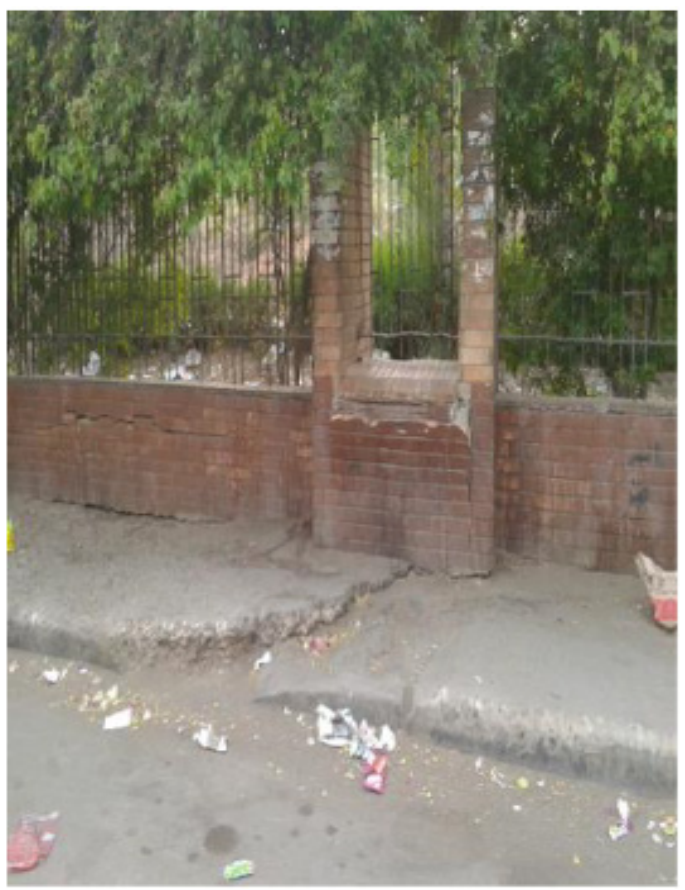

Figure 1. Damaged sidewalks in the streets of Cairo

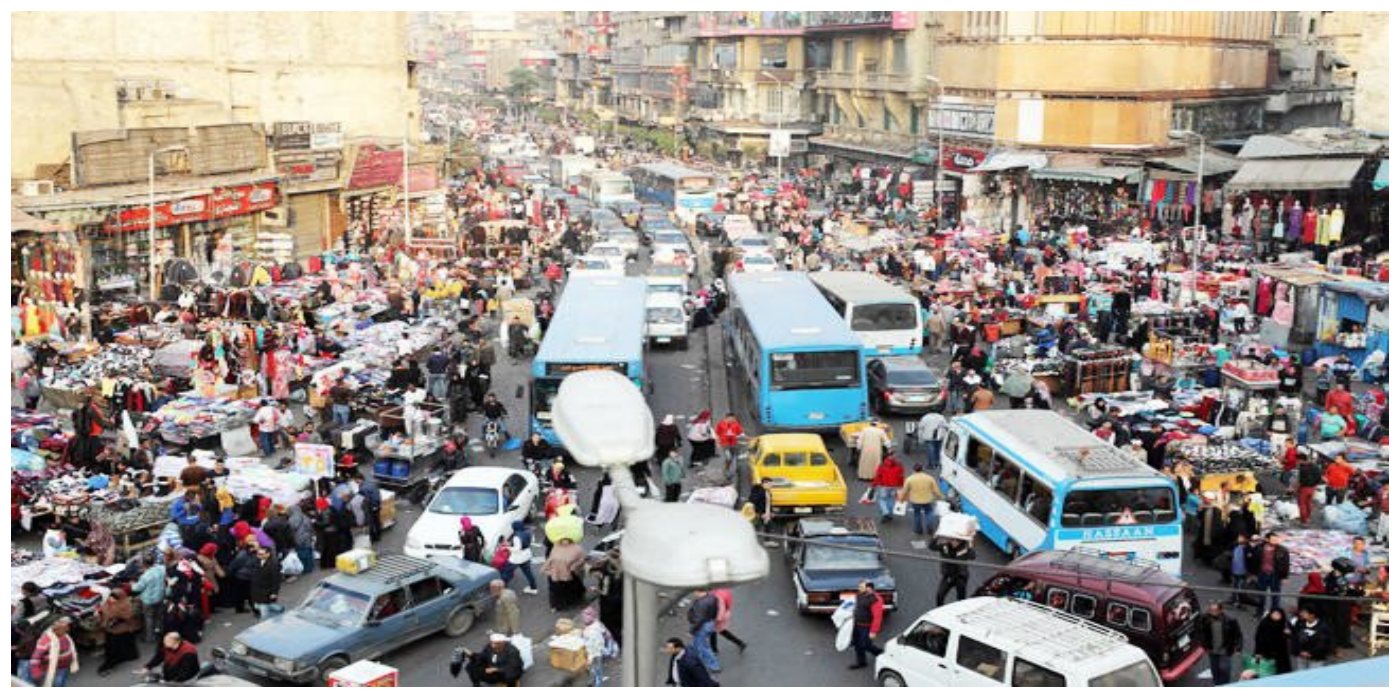

Figure 2. Pedestrians walking on the streets with cars 
In other cases, the condition of the streets is acceptable, even good, and allows pedestrian walking, as shown in Figure 3, which illustrates the development of Baghdad Street in El-Korba area, which is one of the good streets characterized by a distinctive architectural character, combines Islamic architecture and Coptic architecture.

\subsubsection{Width of the Sidewalk}

Pedestrians need convenient sidewalks to ensure comfort in walking in streets [19]. One of the difficulties monitored in the study area is the widths of the sidewalks in Cairo streets, which are very uneven and do not abide by the standards. The average width is known to be 91.44 $\mathrm{cm}$, according to the "District's Department of Transportation". Thus, pedestrians cannot constantly walk without moving up and down from the sidewalk. The sidewalks do not abide by the urban design standards, thus affecting the walkability of the pedestrian and affecting his comfort of walking [20].

\subsubsection{Acquisition of Sidewalks by Cafés}

The cafés and restaurants occupy the ground and overlook the sidewalks along the streets of Cairo. Figure 4; use the sidewalk space and put down their tables and chairs, making the pedestrians unable to walk pleasantly [5].

\subsection{The Status of Side Corners}

Side Corners have affected pedestrians in many ways. Firstly, they take up almost all the sidewalk width, affecting pedestrians' walking permeability [5]. For instance, a kiosk could be at the corner of a street that forces the pedestrian to go off the sidewalk and the walk-in street itself along with the cars, putting the person's life at risk [21].

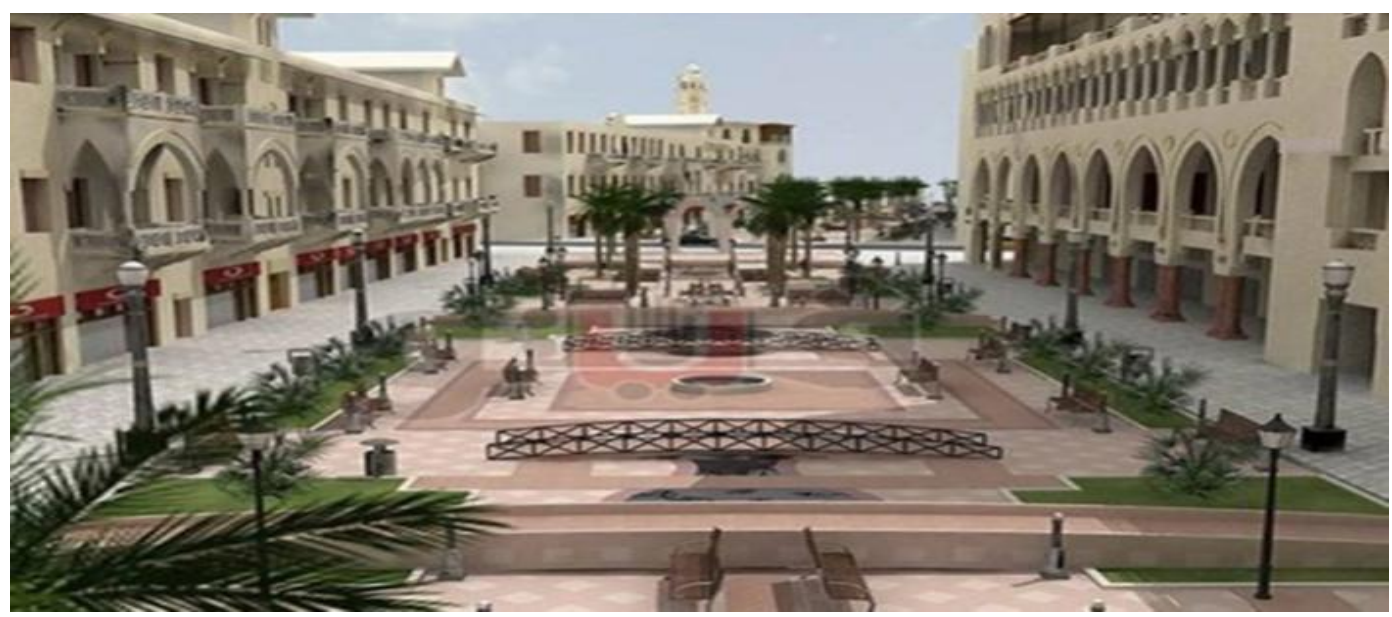

Figure 3. Baghdad Street in El-Korba area as a case of good condition
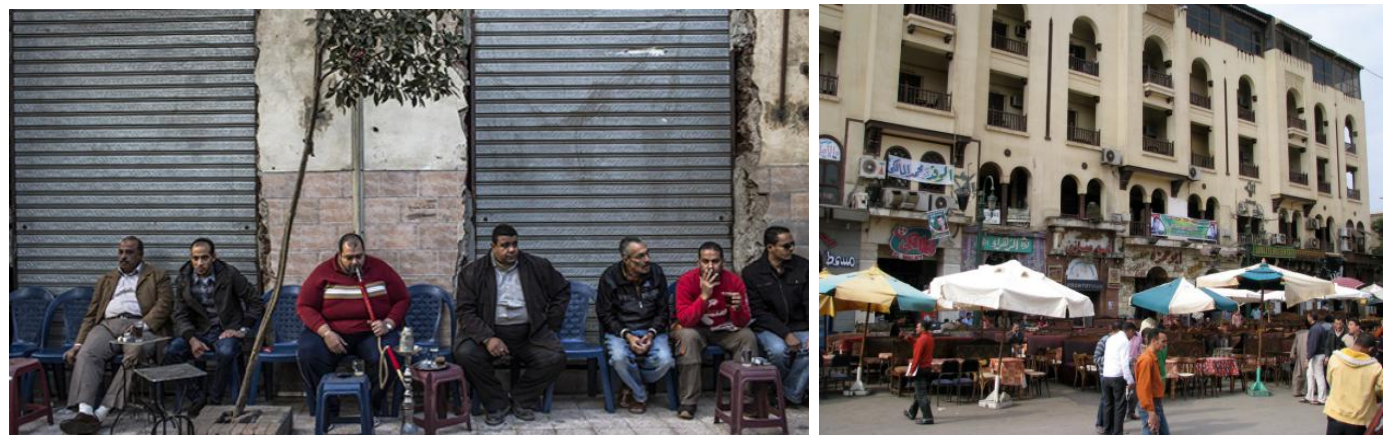

Figure 4. Chairs and tables take up the space of sidewalks 


\section{Checking Levels of Pedestrians' Satisfaction in Cairo streets}

Pedestrian Level of Service (PLOS) is a multifaceted expression representing the working condition of walking facilities and the satisfaction level of pedestrian experience while using these facilities [22]. Using qualitative data sets, it needs to develop PLOS models for pedestrian facilities such as sidewalks, signalized intersections, and un-signalized intersections [22].

During the day, time, and season, the movement of pedestrians differs from one moment to another and from one place to another [23, 24]. This is considered to help pedestrians walk without allowing the condition of time and weather to affect them. For instance, the Basilica Square in Cairo was full of gardens, trees, and plants that act as a self-shading for pedestrians from hot and dry summer weather in Cairo. Furthermore, pedestrians must respect the movement and the flow of people walking to avoid collisions and chaotic bumps [25].

Pedestrians have different thoughts regarding this aim. However, there are many reasons for users' dissatisfaction. In this scope, El-Ghandour [18] interviewed pedestrians in Cairo streets in four groups, which ended with the following interpretations:

- Group no. 1: Walking conditions did not satisfy them because of robbing, harassing, and unsafe due to the cars prioritizing in the streets.

- Group no. 2: It did not concern the conditions because athletes can walk even with the bad pavements because of its healthy ability.

- Group no. 3: It does not consider this issue since they are poor, caring about making their living.

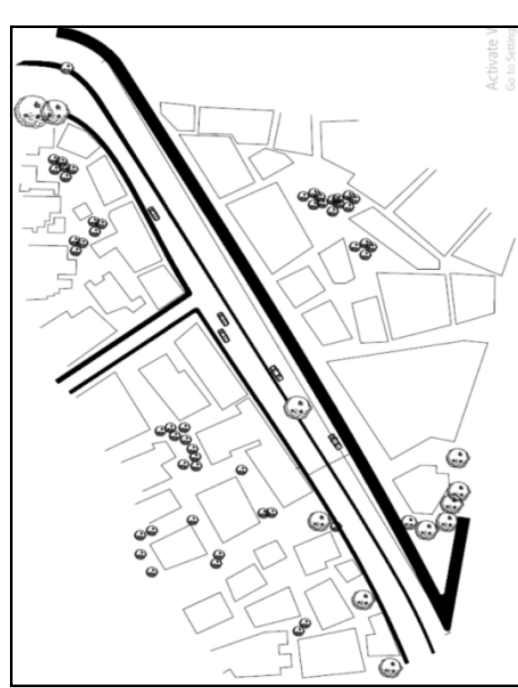

- $\quad$ Group no. 4: They walk twice per day to and back from their school. They astonished the interviewer pointing to several problems as receiving verbal harassment, dumping garbage in the streets, pavements, and sidewalks were either damaged or taken up by cars to almost two or three lanes. Overall, they described the streets in one word, "disgusting".

When pedestrians were asked what they would recommend enhancing their walking, a fine should be applied and not be bribed later so that people could not underestimate the fine. Moreover, cars in the streets should follow the law and regulations to enhance the walking experience [18].

\section{Investigation into Two-Case Studies: El-Korba and Al-Azhar Streets}

\subsection{Defining the Two-Case Studies}

\subsubsection{El-Korba Area}

El-Korba is a great market area, a lovely shopping district surrounded by old villas and apartment buildings fascinating to see. Its streets are fine with active frontages that create continuous and well-defined urban routes, as shown in Figure 5. Besides, these streets create a sense of enclosure, which provides a strong sense of place [26]. Édouard Empain found El-Korba district in the Heliopolis quarter in 1906. It is well-known for its fabulous, picturesque architecture, and it is full of classic French architecture designs. Moreover, this area is a place for socialites. El-Korba Street is one of the most famous streets in Cairo [27].

Figure 5. Section and plan of El-Korba Street, Cairo 


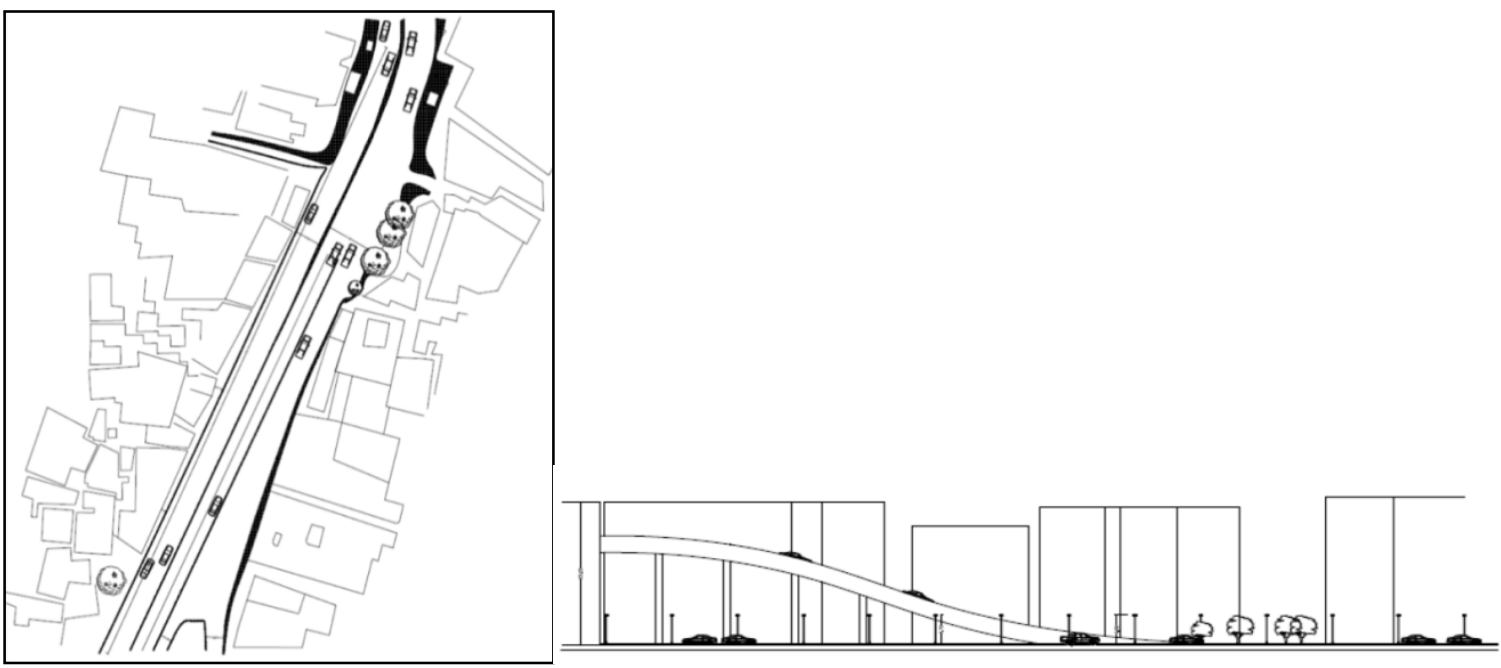

Figure 6. Section and plan of Al-Azhar Street, Cairo

\subsubsection{Al-Azhar area}

Al-Azhar area goes back up to 1,051 years. This area is well known for its Islamic patterns and architecture. It is full of different mosques, each with a unique design, but at the same time, they are all aligned together, as shown in Figure 6. Moreover, it is well known for its famous streets such as Al-Hussein, where people visit it due to many cases.

Al-Azhar Street is one of the most important tourist streets in Cairo city. The street starts from the El-Ataba area and ends in El-Darasa. Al-Azhar Street connects the most significant streets of historic Cairo city and its areas [28 \& 29].

\subsection{Procedures of the Investigation}

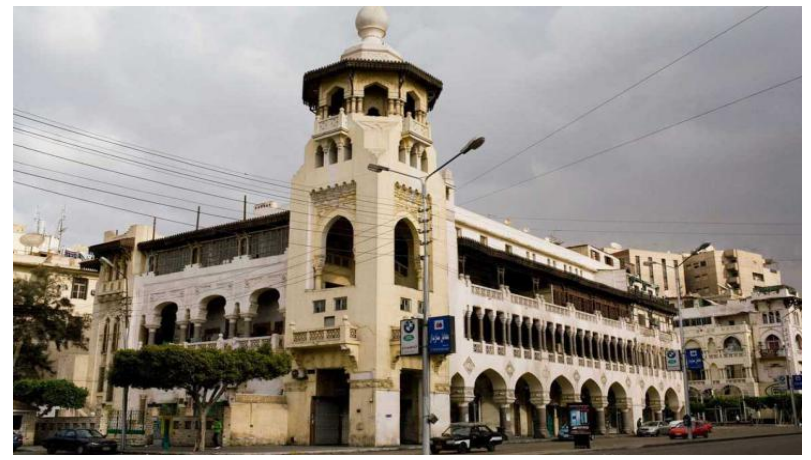

Figure 7. El-Korba Street

A case study is taken in El-Korba area, specifically in the main street, Figure 7. First, the study conducted a survey covering people of various ages groups of its citizens, whether they live in the study area or not, and Egyptians outside the country and have visited the El-Korba. The survey consists of 12 questions regarding Cairo's streets in general and El-Korba specifically.

The same questions were asked again about Al-Azhar area, especially in the main street, Figure 8. Then, according to the survey, the data is collected and analyzed. Moreover, the data were summarized to get to the conclusions of the different causes.

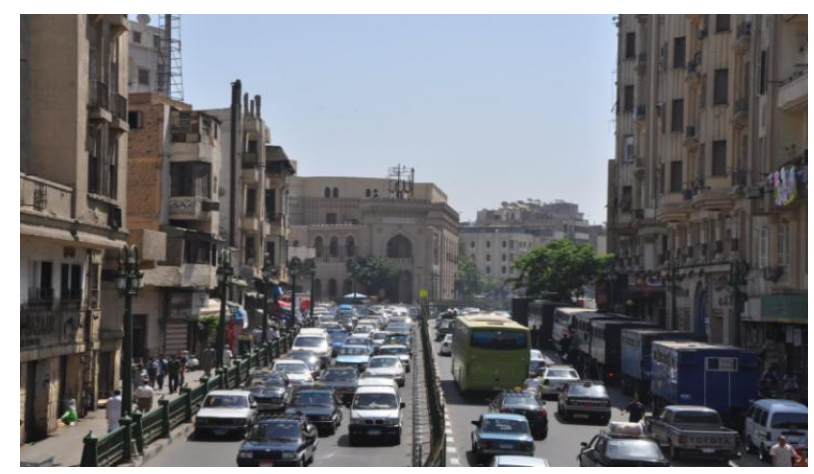

Figure 8. Al-Azhar Street

\subsection{Characteristics of the Participants}

A total of 335 persons participated and were surveyed for three months starting from December 2020. The sample included 158 residents of El-Korba district, while 177 participants were randomly selected among Al-Azhar residents. The distribution of the participants' social and demographic characteristics, such as gender, age, marital status, and education level, are shown in Table 1, which is illustrated in Figure 9. 
Table 1. Social and Demographic characteristics of the participants

\begin{tabular}{|c|c|}
\hline \multicolumn{2}{|c|}{ GENDER } \\
\hline Type & Percentage \\
\hline Male & $53 \%$ \\
& \\
\hline & \\
\hline & \\
\hline
\end{tabular}

\begin{tabular}{|c|c|}
\hline \multicolumn{2}{|c|}{ AGE } \\
\hline Range & Percentage \\
\hline Below 20 & $12.12 \%$ \\
\hline $20-29$ & $27.27 \%$ \\
\hline $30-39$ & $12.12 \%$ \\
\hline $40-49$ & $15.16 \%$ \\
\hline Above 50 & $33.33 \%$ \\
\hline
\end{tabular}

\begin{tabular}{|c|c|}
\hline \multicolumn{2}{|c|}{ EDUCATION } \\
\hline Education level & Percentage \\
\hline Uneducated & $36.36 \%$ \\
\hline Basic & 30.30 \\
\hline Secondary & 3.030 \\
\hline Technical Education & 12.13 \\
\hline Higher Education & $18.18 \%$ \\
\hline
\end{tabular}

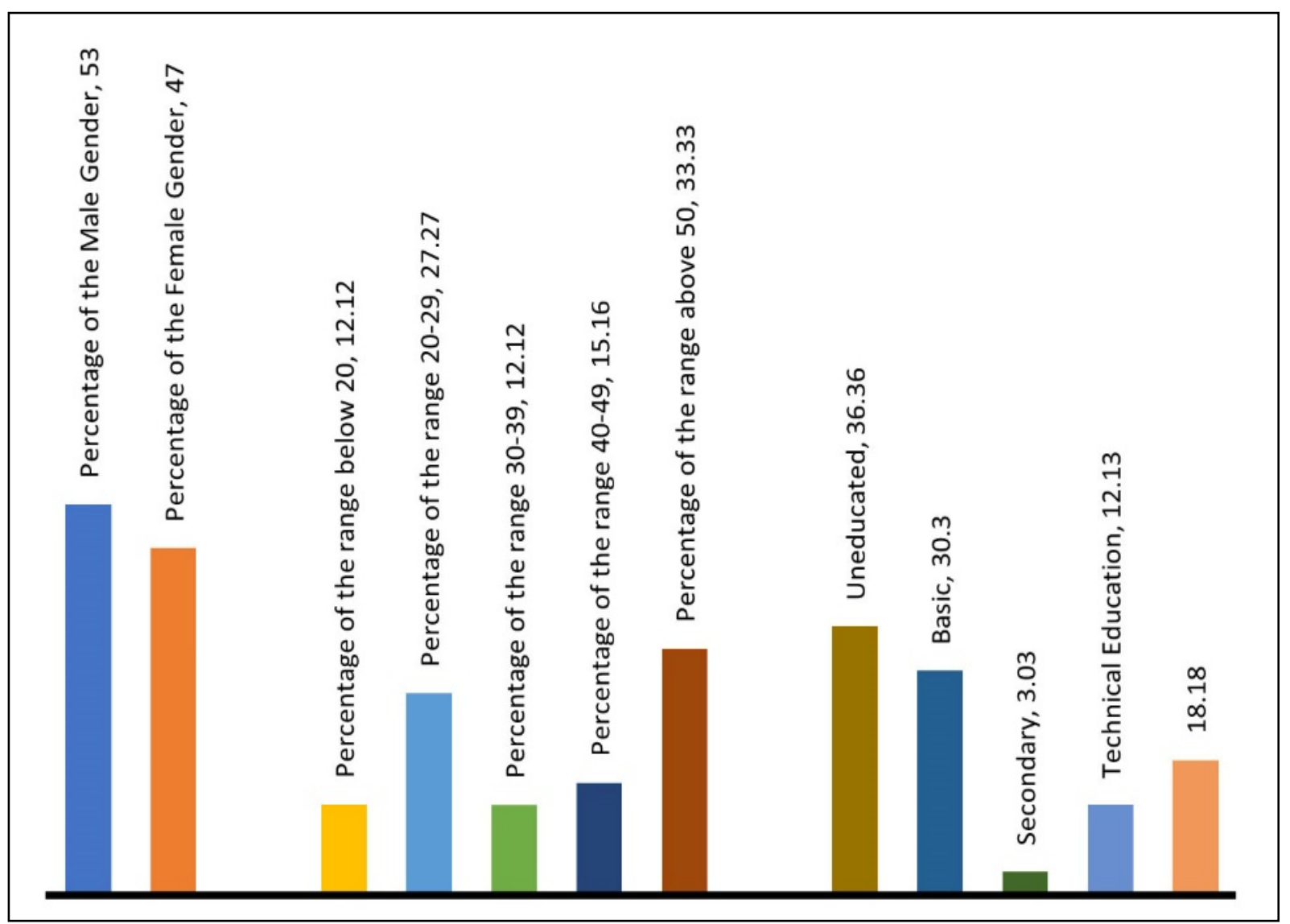

Figure 9. Social and Demographic characteristics of the participants 


\subsection{Data Collection}

This research used a qualitative questionnaire for data collection, collected from El-Korba Street, Figure 10, and Al-Azhar Street, Figure 11, considering them as a representation covering the status of the streets in Cairo city. This study analyzed and compared the collected data in the result section.

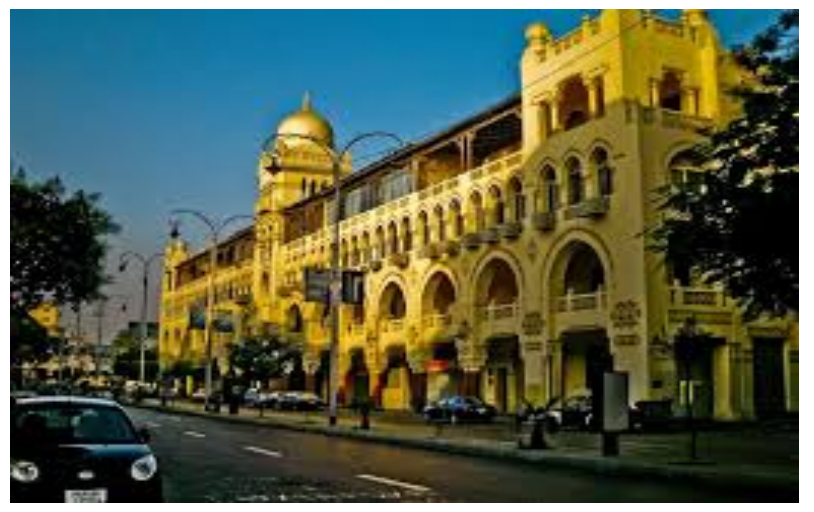

Figure 10. El-Korba Street

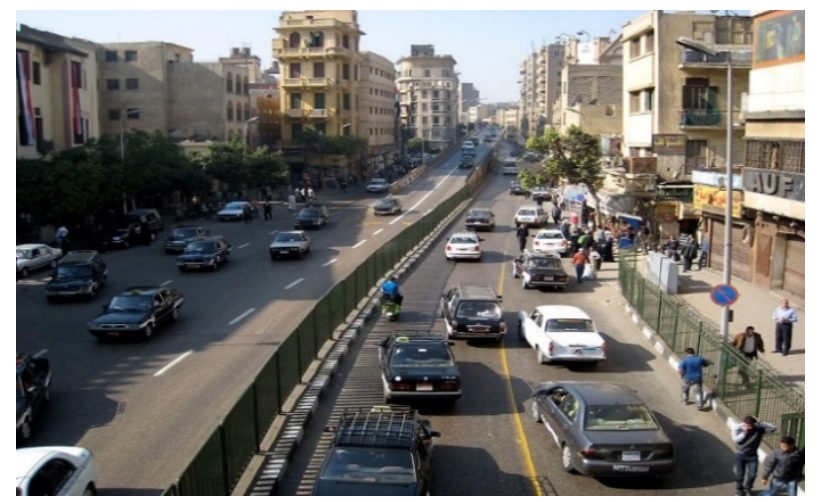

Figure 11. Al-Azhar Street

The questionnaire was divided into four sections; the first section presented the demographic characteristics of participants such as age, gender, educational level, etc. The second section presents general questions regarding the participants' walking experiences. The third section measures the participants' physical perception of the street, such as quality of pavements, lighting features, street furniture, direction signage, crossing lines, speed bumps, signs, and street greenery. The fourth section measures the participants' social perception, which includes safety, comfort, usability, attractiveness, and waking pleasures, as shown in the appendix.

\section{Results of the Two-Case Studies Investigation}

The results of the survey were collected and summarized in the form of tables. The results were divided into two sections; section one represents the results of El-Korba street survey, while section two represents the results of Al-Azhar street survey. After conducting the survey, the data were analyzed and explained as shown below.

\subsection{Results of Investigating El-Korba Street}

As shown in Table 2, the data was collected, showing the percentage of people affected or not according to each question specified in each row. It is seen that the percentage of people who prefer walking in El-Korba was almost $80 \%$, and the percentage of people who in general find problems in the street of Cairo was $70 \%$. Moreover, $55 \%$ of people enjoy walking down the El-Korba. Furthermore, people who find obstacles in El-Korba Street are less than half.

\subsection{Result of Investigating Al-Azhar Street}

As conducted at the first case, the second case data were collected in Table 3, which shows the percentage of people affected or not according to each question specified in each row. It is seen that the percentage of people who prefer walking in Al-Azhar was $33 \%$, and the percentage of people who in general find problems in the Cairo streets was $67 \%$. Moreover, $33 \%$ of people enjoy walking down Al-Azhar street. However, people who found obstacles in that street were less than $62 \%$.

In Table 4, According to participants' responses, the survey revealed the obstacles that faced the participants in Cairo streets and why the participants liked and disliked walking in. 
Table 2. Percentage of people who answered, "El-Korba Street" survey

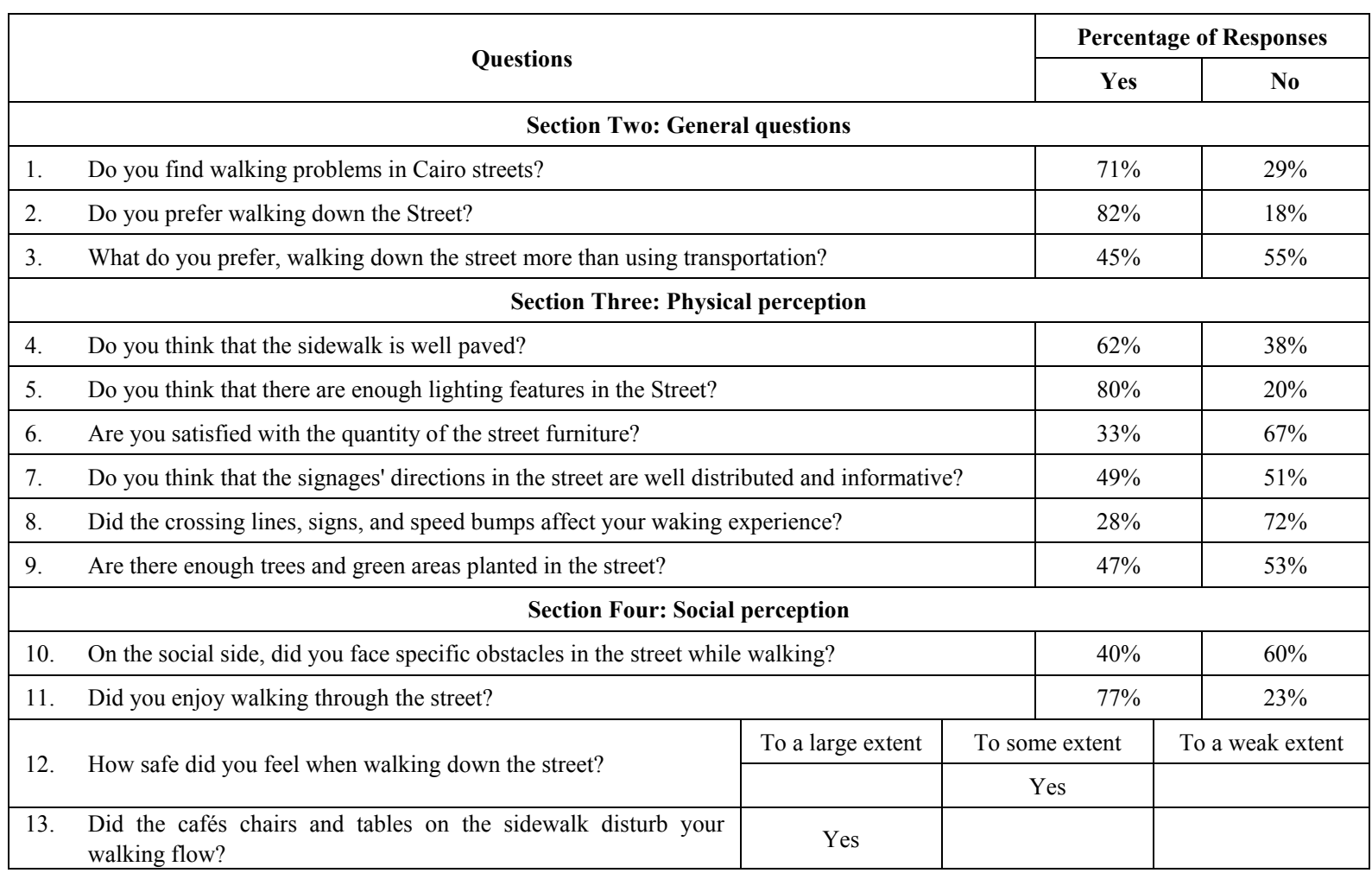

Table 3. Percentage of people who answered, “Al-Azhar Street” survey

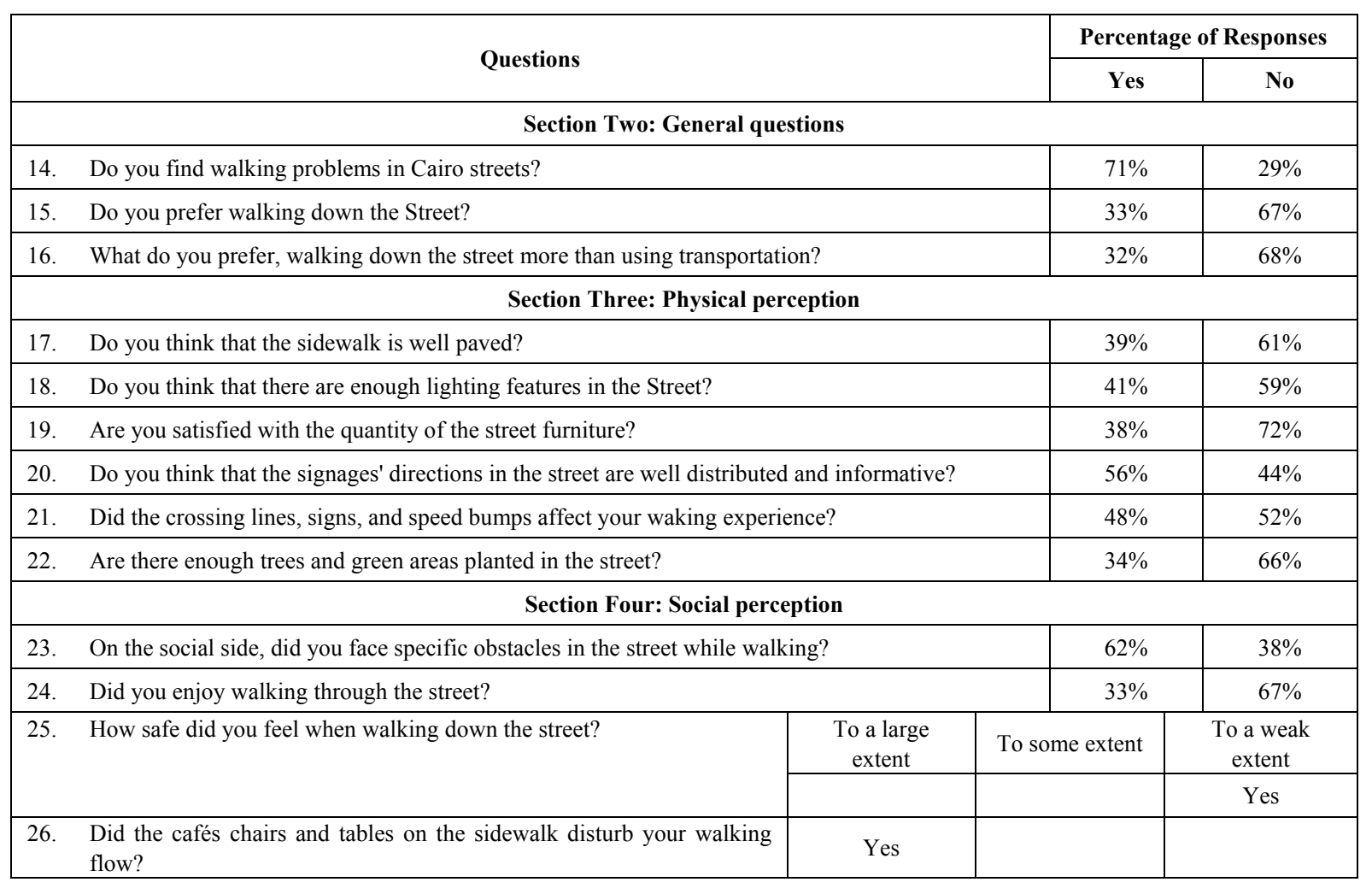


Table 4. Common comments of the participant's walking experience in "El-Korba" and "Al-Azhar" Streets

\begin{tabular}{|c|c|c|}
\hline \multicolumn{3}{|c|}{ In El-Korba and Al-Azhar Street } \\
\hline Why do people like walking? & Why do people dislike walking? & Obstacles faced in the Streets of Cairo \\
\hline $\begin{array}{ll}\text { - } & \text { Wide Sidewalks } \\
\text { - } & \text { Shops } \\
\text { - } & \text { Health } \\
\text { - } & \text { Entertainment } \\
\text { - } & \text { Architectural elements } \\
\text { - } & \text { Cairo's streets are life at night } \\
\text { - } & \text { Relaxing } \\
\text { - } & \text { Relatively Clean pathways } \\
& \text { weather }\end{array}$ & $\begin{array}{ll}\text { - } & \text { Modes of Transportation is fast } \\
\text { - } & \text { Beggars } \\
\text { - } & \text { Harassment } \\
\text { - } & \text { Weather chairs (in some areas) } \\
\text { - } & \text { No greenery }\end{array}$ & $\begin{array}{ll}\text { - } & \text { Unclear pathway } \\
\text { - } & \text { Broken pavements } \\
\text { - } & \text { Kiosks } \\
\text { - } & \text { Width in some areas tiny } \\
\text { - } & \text { crowdedness }\end{array}$ \\
\hline
\end{tabular}
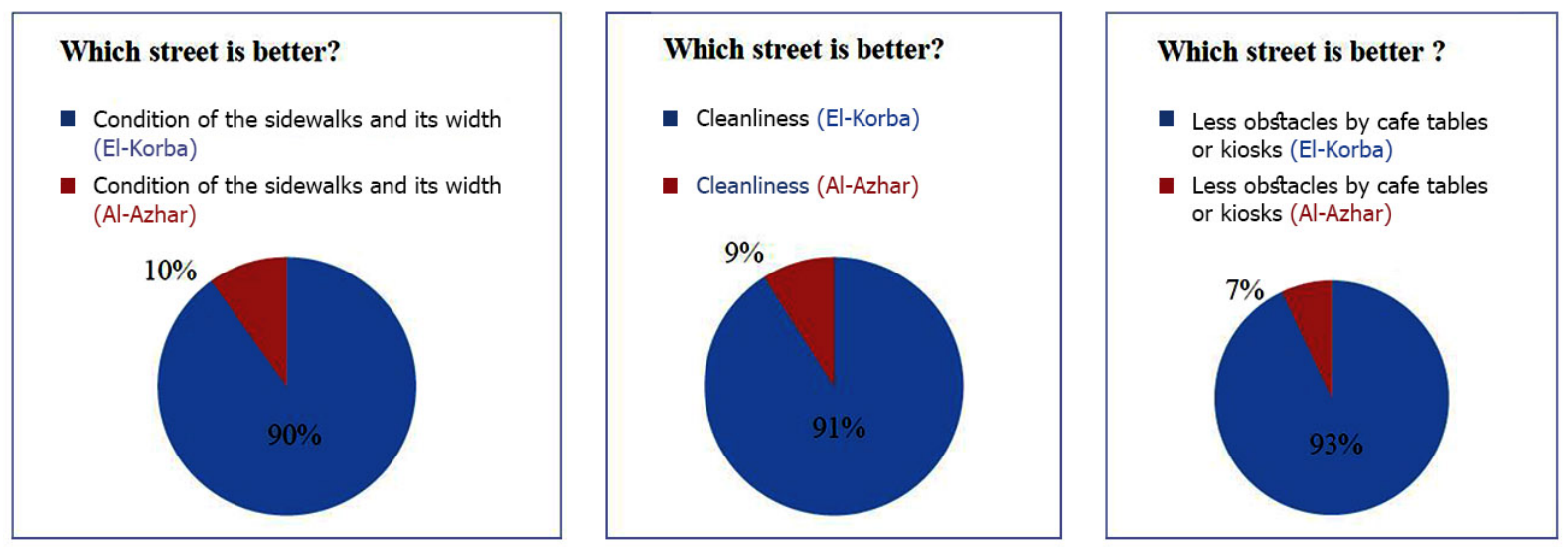

Figure 12. Comparison between the two case studies (El-Korba and Al-Azhar Streets)

\subsection{A Comparison between the Results of the Two Case Studies}

This study, through Figure 12, presents a comparison between the two case studies using pie charts to set a clear conclusion.

Pedestrians have many difficulties regarding walking difficulties in Cairo streets. The survey showed that almost $70 \%$ of the people suffer from walking difficulties. On the other hand, the study showed that pedestrians enjoyed walking more in El-Korba, almost $80 \%$. This contradiction shows that El-Korba Street has features that are not generally applied in Cairo's streets. Firstly, El-Korba Street is relatively clean and is void of garbage compared to other streets in Cairo, which is unpleasant to pedestrians. Thus, it allows showing its architectural elements, which are appealing to pedestrians. Moreover, the width of the sidewalk in El-Korba Street is wide enough as it allows pedestrians to be relaxed while walking and does not force them to go off and, on the sidewalk, due to different levels and put them at risk due to the cars in contradictory with the other streets in Cairo.

Moreover, the district administration that governs El-Korba district prohibits kiosks and shops that invade the sidewalk and stop people's flow of movement. However, some cafés invade the sidewalk. Furthermore, weather plays an important role in the pleasure of walking, as it might be with the pedestrian's wants or not. Additionally, El-Korba architectural elements integrated with the building allow shade, which allows a more delightful walk. Finally, harassment in the streets affects the pedestrians, thus not feeling safe while walking. However, Al-Azhar gets almost a vice versa result as pedestrians do not enjoy walking by $67 \%$ of this street. At the same time, they walk on it as the traffic is very nerve-racking. Pedestrians also do not have proper sidewalks as it is taken up by shops and kiosks, forcing them to walk down the streets, and there is no greenery.

This case study shows that El-Korba Street almost avoids all the causes mentioned above in the reasons behind this problem. Therefore, more than half the people enjoy walking in this street and at the same time show a bad impression generally on other streets of Cairo and as seen in this study, such as Al-Azhar street. The analysis shows that cleaner, more organized, and street safety applications would enhance the experience for users to walk in the streets pleasurably.

\section{Discussion}

This study finds that the streets' cleanliness, sidewalks, and general status are among the key factors that meet pedestrians' walking satisfaction. The increasing percentage of carbon emissions released from vehicles creates a discomfort environment for walkability [10]. According to previous theories, safety is the second need that directly comes after fulfilling the psychological needs 
of a person, which aids and supports the findings of this study showing that the disliked conditions of the sidewalks mainly arise from lack of safety. This interpretation is reached through the different opinions of pedestrians expressing their deepest needs to enjoy a simple walk in their area.

On the other hand, another theory in 2005 suggested that the ability to fulfill and satisfy the person's needs for shopping and entertainment is called usefulness, which is of more importance than safety. For it to be useful, it must have some cleanliness that makes something attractive. For instance, lack of greenery in both streets eliminated the factor of attractiveness and thus cleanliness, which is a component of usefulness that is not there.

Both theories are in sync with the findings of this study, where safety and usefulness, which are appointed to them in this study as attractiveness, are both priorities and requirements for pedestrians to walk in the streets. This study was mainly done qualitatively and did not list the findings as to the previous theories in ranking order. Therefore, the findings of this study cannot be generalized because it did not cover the whole community, but they are a definite mark for future and more research.

In this study, the lack of either theory in either street studied shows significant evidence of why people dislike a street more than the other or vice versa. The levels of satisfaction of pedestrians are also in link with the need of the pedestrian. The need of the pedestrian is characterized according to the priority of each user. So, for instance, harassment was one of the factors that caused people to dislike walking in the streets. This issue might not affect the other gender, which in other terms, walking in the street for him is safe and useful.

However, the cleanliness of the street is another key factor that affects the pedestrian and adds to the difficulties of walking [31]. Lack of cleanliness has a huge negative impact on the favorability of walking in the street. Over 90\% dislike walking in Al Azhar Street and rather favor El-Korba due to this factor. This implies that the local authorities should consider rehabilitating and restoring the lives of those affected streets to return the identity and entity of the street to allow pedestrians to enjoy walking once again.

Several issues lack the essence that could be named under the comfort and safety group as they influence pedestrian walking. Furthermore, one of the main factors is shop owners who invade the sidewalk of the streets with their goods, or if cafés, their tables, and chairs. This is mainly seen in Al-Azhar Street and sometimes in El-Korba Streets. Moreover, cars are dominant, and they take over the streets. This adds to the difficulties of walking, which affects the pedestrians' experience.

Other factors that were not considered since it was not added to the survey and was not analyzed, such as vendors on the streets as they could sometimes be off the streets. That is why we could not see the effect of this factor on pedestrians. Furthermore, we need to consider that although most people on the street come from a similar demographic background, there will still be variations in their point of view and perception of the difficulties they face by walking in the streets due to the different priorities in each person's life.

This study's findings showed that the results make sense and are related; moreover, the questionnaire analyzed the results and discussed them. The previous tables and charts helped organize the data with numbers for further analysis and cleared out the different likes and dislike within both case studies to reach a clear result that was able to be discussed along with different theories for evidence.

\section{Conclusions}

It is indubitable, from this research, that there are several reasons why it is not preferred to walk in the streets in Cairo. This problem would need a constant inflow of running costs, but at the same time will help with the satisfaction of the pedestrian. This research aims to clarify and show the possible different factors that affect the walking difficulties and how accordingly could be enhanced and add usefulness, safety, and cleanliness to the streets of Cairo.

This study showed the different reasons that prevented the pedestrians from walking comfortably in the streets. Therefore, it is recommended to abide by the urban standards, which help allow more space for pedestrians to walk if they are alone or with a few people. Moreover, constant maintenance and checkups on the sidewalks will help avoid damages that do not force people to walk on them but rather walk on the streets, and the government should not allow obstacles to be in the sidewalk area that could affect the walkability flow. Furthermore, nature as an attractive feature has an important role in enhancing pedestrians' experience by caring for various issues as safety, shading, and adding a picturesque view for the walker.

This paper concludes on the practical usefulness of prioritizing implementing urban design strategies and policies that increase walking accessibility levels in Cairo streets. Using quantitative strategies, we were able to see and count the percentage of people who answered with their opinions and using qualitative analytical skills to discuss the issues behind the difficulties of walking, Hence, aiming to suggest the policymakers and people in authority to ease and enhance the streets of Cairo and guide them according to the priorities of the pedestrian and their needs.

The findings in this paper can enlighten and give a push start for the policymakers to start and make the streets of Cairo a better place. This research identified the main features of the street background in Cairo with two case 
studies. However, other dynamics could affect the walking difficulties that were not studied, as the study was done on a microscale using a small, compacted questionnaire to get a brief and investigate the perception of the pedestrians.

The results and findings show the need for authorities to act and planning skills to reorient the city of Egyptian planning. While this study added to the understanding and comprehension of the user wants and needs, it is restricted to the people who have answered the questionnaire, the location where the case studies were taken, and the season of the year that people walk in. It is recommended that further studies and more detailed examination of different areas and time, with nowadays technology, can help see more perspectives on the problem that was not accounted for in this research. Moreover, while questioning the people for better city planning, community participation is vital to integrate the users' needs. This is the key to showing users that their difficulties are meaningful and important and will be taken care of.

\section{Appendix}

\section{Pedestrian Walking Experiences Questionnaire}

\begin{tabular}{|c|c|c|}
\hline \multicolumn{3}{|c|}{ Pedestrian Walking Experiences Questionnaire } \\
\hline \multicolumn{3}{|c|}{ Section One: The participants' demographic characteristics } \\
\hline $\begin{array}{l}\text { Gender: } \\
-\quad \text { Male } \\
-\quad \text { Female }\end{array}$ & $\begin{array}{ll}\text { Age: } & \\
\text { - } & \text { Below } 20 \\
\text { - } & 20-29 \\
\text { - } & 30-39 \\
\text { - } & 40-49 \\
\text { - } & \text { Above } 50\end{array}$ & $\begin{array}{ll}\text { Education level: } \\
\text { - } & \text { Uneducated } \\
\text { - } & \text { Basic } \\
\text { - } & \text { Secondary } \\
\text { - } & \text { Technical Education } \\
\text { - } & \text { Higher Education }\end{array}$ \\
\hline $\begin{array}{ll}\text { How many tim } \\
\text { - } & \text { My first } \\
\text { - } & \text { A coupl } \\
\text { - } & \text { Sometin } \\
\text { - } & \text { More of } \\
\text { - } & \text { Daily } \\
\text { - } & \text { Weekly } \\
\text { - } & \text { Monthly }\end{array}$ & this street? & \\
\hline \multicolumn{3}{|c|}{ Section Two: General questions } \\
\hline \multicolumn{3}{|c|}{$\begin{array}{l}\text { Do you find walking difficulties in Cairo streets? } \\
\text { - Yes } \\
\text { - } \quad \text { No }\end{array}$} \\
\hline \multicolumn{3}{|c|}{$\begin{array}{l}\text { Do you prefer walking down the Street? } \\
\text { - Yes } \\
\text { - } \quad \text { No } \\
\quad \text { Why? }\end{array}$} \\
\hline \multicolumn{3}{|c|}{$\begin{array}{l}\text { What do you prefer, walking down the street more than using transportation? } \\
\text { Why? }\end{array}$} \\
\hline \multicolumn{3}{|c|}{ What encourages/discourages you from walking? } \\
\hline \multicolumn{3}{|c|}{$\begin{array}{l}\text { How can you briefly describe the status of "sidewalks" in Cairo Streets? (For example, status, width, acquisitions, and pavements } \\
\text { finishing). }\end{array}$} \\
\hline \multicolumn{3}{|c|}{ Form your opinion, how can we improve the streets to be more convenient for pedestrians? } \\
\hline \multicolumn{3}{|c|}{ Section Three: Physical perception } \\
\hline \multicolumn{3}{|c|}{$\begin{array}{l}\text { Do you think that the sidewalk is well paved? } \\
\text { - Yes } \\
\text { - } \quad \text { No }\end{array}$} \\
\hline \multicolumn{3}{|c|}{$\begin{array}{l}\text { Do you think that there are enough lighting features in the Street? } \\
\text { - Yes } \\
\text { - No }\end{array}$} \\
\hline $\begin{array}{l}\text { Are you satisfi } \\
\text { - } \quad \text { Yes } \\
\text { - } \quad \text { No }\end{array}$ & the street furniture? & \\
\hline
\end{tabular}




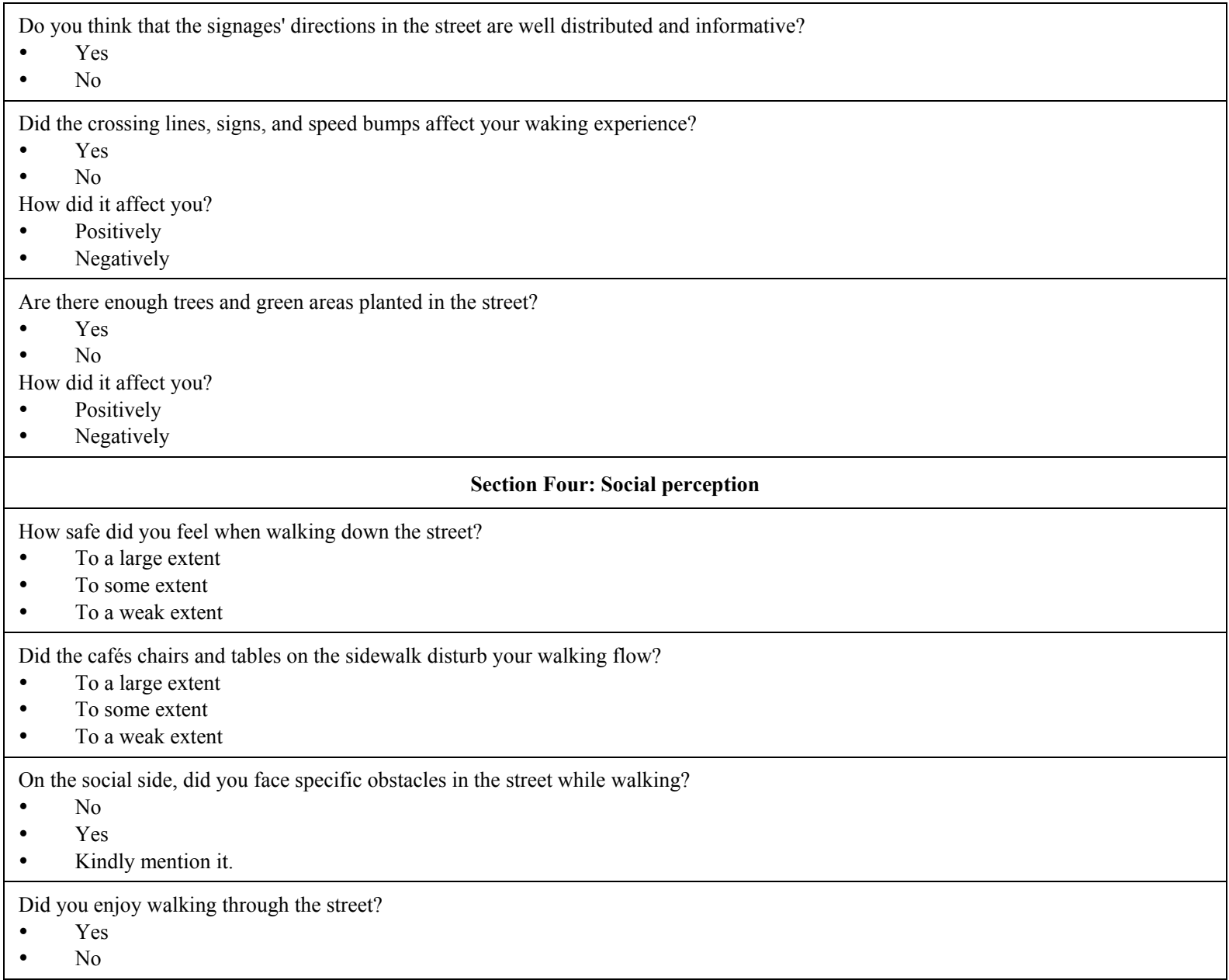

\section{REFERENCES}

[1] Laura Frank. (2010). Streetscape Design: Perceptions of Good Design and Determinants of Social Interaction. Master, at Arts in Planning, University of Waterloo, Waterloo, Ontario, Canada.

[2] Saba Doulabi, Hany M. Hassan, Mark R. Ferguson, Saiedeh Razavi, and Antonio Paez. (2021). Exploring the determinants of older adults' susceptibility to pedestrians' incidents. Accident Analysis \& Prevention. ISSN: 0001-4575, vol. 155, pp. 106100. DOI: https://doi.org/10.1016/j.aap.2021.106100. Available at: https://www.sciencedirect.com/science/article/pii/S000145 7521001317.

[1] BBC News. (20 Jan 2016). Cars on England's roads increase by almost 600,000 in a year. Accessed on 9 July 2021. Available at: https://www.bbc.com/news/uk-england-3531 2562? piano-modal.

[3] B. Soemardiono and M. Rachmawati. (2020). The innovative and sustainable streetscape design based on community participation in Surabaya, Indonesia, in Advances in Science, Technology and Innovation, Springer Nature, pp. 23-30. Available at: https://www.scopus.com/inward/record.uri?eid=2-s2.0-850 98011763\&doi $=10.1007 \% 2 f 978-3-030-17308-1 \_2 \&$ partne $\mathrm{rID}=40 \& \mathrm{md} 5=730 \mathrm{fc} 110826 \mathrm{db} 2 \mathrm{a} 43 \mathrm{~b} 0 \mathrm{c} 829 \mathrm{e} 7 \mathrm{f} 0711 \mathrm{de}$.

[4] Dalya M. Hassan, Yasser M. Moustafa, and Sherif M. El-Fiki. (2019). Ground-floor façade design and staying activity patterns on the sidewalk: A case study in the Korba area of Heliopolis, Cairo, Egypt. Ain Shams Engineering Journal. ISSN: 2090-4479, vol. 10 (3), pp. 453-461. DOI: https://doi.org/10.1016/j.asej.2018.12.006.

[5] Analiz Ochoa. (2021). Filling the Gaps: Reimagining Public Space as a Continuum. Master in Architecture, at Faculty of Graduate and Post-Doctoral Affairs, Carleton University, Ottawa, Ontario, Canada. Retrieved from: https://curve.carleton.ca/3c515101-980d-4706-bbb1-bdd74 2cde294.

[6] Rania Rushdy Moussa, Ayman Hassaan Mahmoud, and Tarek Moustafa Hatem. (2020). A digital tool for integrating renewable energy devices within landscape elements: Energy-scape online application. Journal of Cleaner Production. ISSN: 0959-6526, vol. 254, pp. 1-13. DOI: https://doi.org/10.1016/j.jclepro.2019.119932.

[7] Usama Konbr. (2011). Environmental Handling of Hard-scaping Elements as an Approach to SustainabilityApplying to the city of Tanta. Journal of Al-Azhar University Engineering Sector (JAUES). ISSN: 1687-8418, vol. 6 (21), pp. 1138-1149. Retrieved from: 
https://www.researchgate.net/publication/327977522_Envi ronmental_Handling of Hard-scaping_Elements_as_an_A pproach_to_Sustainability-_Applying_to_the_city_of_Tan ta.

[8] Ahmed Mohamed Thabet. (2021). Reimaging Streets: A Design Approach for Enhancing Walkability in old Cities, Case Study: El Gomhouria Street, Mansoura. MEJ. Mansoura Engineering Journal. ISSN: 1110-0923, vol. 46 (2), pp. 46-57. Doi: https://doi.org/10.21608/bfemu.2021.1 69740 .

[9] Rania Rushdy Moussa, Mahmoud M. M. Mansour, and Naglaa Mohamed Yossif. (2021). Statistic Equation to Estimate the Amount of CO2 Emission Produced from High Traffic Density Roads. WSEAS Transactions on Power Systems. ISSN: 1790-5060, vol. 16, pp. 78-86. DOI: https://dx.doi.org/10.37394/232016.2021.16.8.

[10] Katherina Grafl, Heike Bunte, Katrin Dziekan, Holger Haubold, and Manfred Neun. (2018). Framing the third cycling century, bridging the gap between research and practice. German Environment Agency. Available at: https://repository.difu.de/jspui/handle/difu/256755.

[11] Emilio Ortega, BelÉN MartíN, MarÍA Eugenia LÓPez-Lambas, and Julio A. Soria-Lara. (2021). Evaluating the impact of urban design scenarios on walking accessibility: the case of the Madrid 'Centro' district. Sustainable Cities and Society. ISSN: 2210-6707, vol., pp. 103156. DOI: https://doi.org/10.1016/j.scs.2021.103156.

[12] Suzanna Allen Massingue and Daniel Oviedo. (2021). Walkability and the Right to the city: A snapshot critique of pedestrian space in Maputo, Mozambique. Research in Transportation Economics. ISSN: 0739-8859, vol. 86, pp. 101049. DOI: https://doi.org/10.1016/j.retrec.2021.101049.

[2] Carlo Luiu. (2021). Pedestrian Safety, Older People, in International Encyclopedia of Transportation, R. Vickerman, Editor, Elsevier: Oxford, pp. 429-434. Available at:https://www.sciencedirect.com/science/article /pii/B9780081026717101630.

[13] M. Eugenia López-Lambas, J. Manuel Sánchez, and Andrea Alonso. (2021). The walking health: A route choice model to analyze the street factors enhancing active mobility. Journal of Transport \& Health. ISSN: 2214-1405, vol. 22, pp. 101133. DOI: https://doi.org/10.1016/j.jth.2021.10113 3.

[14] Jehan M. Ibrahim, Hannah Day, Jon Mark Hirshon, and Maged El-Setouhy. (2012). Road risk-perception and pedestrian injuries among students at Ain Shams University, Cairo, Egypt. Journal of Injury and Violence Research. ISSN: 2008-2053, vol. 4 (2), pp. 71-78. DOI: https://dx.doi.org/10.5249/jivr.v4i2.112.

[15] Hussam Magdy, Masahiro Shohmitsu, and Toshiyuki Kaneda. (July 2017). Testing the Effect of Sidewalk Design Qualities on Pedestrian Movement at a Commercial Street in Cairo City. In Planning Support Systems for Resilient and Smart Urban Futures. Australia: The University of South Australia, Adelaide, Australia. Retrieved from: https://www.researchgate.net/publication/321797378 Testi ng the Effect of Sidewalk_Design Qualities on Pedestr ian_Movement_at_a_Commercial_Street_in_Cairo_City.

[16] Sahar El-Ghandour. (Fall 2016). Towards more Pedestrian-Friendly Streets in Cairo. Master of Public
Administration, at Public Policy and Administration Department, The American University in Cairo, School of Global Affairs and Public Policy, Cairo.

[17] F. Zwangsleitner. (2020). Form follows comfort: An evidence-based approach to enhancing streetscapes. Journal of Digital Landscape Architecture. ISSN: 23674253 (ISSN), vol. 2020 (5), pp. 94-102. DOI: https://dx.doi.org/10.14627/537690010.

[18] S. Tan and K. Tamminga. (2021). A Vision for Urban Micromobility: From Current Streetscape to City of the Future. ISSN: 21945357 (ISSN); 9783030610746 (ISBN), vol. 1278, pp. 158-167. DOI: https://doi.org/10.1007/978-3 -030-61075-3_16.

[19] Tshwane City Council. (August 2007). Streetscape Design Guidelines. Second Edition ed. Tshwane City, pp.:75. c.p.a.e.m.d. Housing, City planning division - streetscape management section. Retrieved from: http://www.gtkp.co m/assets/uploads/20091129-215719-7868-Streetscape_Des ign_Guidelines\%20SA.pdf

[20] Rima Sahani and P. K. Bhuyan. (2020). Modelling Pedestrian Perspectives in Evaluating Satisfaction Levels of Urban Roadway Walking Facilities. Transportation Research Procedia. ISSN: 2352-1465, vol. 48, pp. 2262-2279. DOI: https://doi.org/10.1016/j.trpro.2020.08.2 89

[21] M. Capitanio. (2019). Attractive streetscape making pedestrians walk longer routes: The case of Kunitachi in Tokyo. Journal of Architecture and Urbanism. ISSN: 20297955 (ISSN), vol. 43 (2), pp. 131-137. DOI: https://dx.doi.org/10.3846/jau.2019.10359.

[22] Usama Konbr. (2019). Smart Sustainable Cities-Vision and Reality. Resourceedings. ISSN: 2537-074X 2537-0731, vol. 2 (1), pp. 101-127. DOI: https://doi.org/10.21625/resourceedings.v2i1.455.

[23] Suheir M. S. Ammar, Kausar Hj Ali, and Nor'Aini Yusof. (2013). The Effect of Participation in Design and Implementation Works on User' Satisfaction in Multi-Storey Housing Projects in Gaza, Palestine. World Applied Sciences Journal, ISSN: 1818-4952. ISSN: 1818-4952, vol. 22 (8), pp. 1050-1058. DOI: https://doi.org/10.5829/idosi.wasj.2013.22.08.2842.

[24] Abdelbaseer Abdelraheem. (2010). Spatial Conditions for Sustainable Communities: The Case of Informal Settlements in GCR. Master, at Department of Urban Planning, Faculty of Engineering, Ain Shams University, https://www.cpas-egypt.com/pdf/Abd_ElBaser/M.SC.

[25] Soha Elsirgany and Nourhan Tewfik. (28 Sep 2016). Exploring Cairo: A walk through the historic grandeur of Korba. News - Travel. Accessed on 16 Jan 2021. Available at: https://english.ahram.org.eg/News/242442.aspx.

[26] Madonna Makram Solban, and Rania Rushdy Moussa (2019). Piezoelectric Tiles Is a Sustainable Approach for Designing Interior Spaces and Creating Self-Sustain Projects. (BSCairo2019) Simulation for a Sustainable Built Environment, Cairo Egypt. IOP Conf. Series: Earth and Environmental Science 397- 012020. DOI: https://doi.org/10.1088/1755-1315/397/1/012020

[27] Rania Rushdy Moussa. (2018). The role of energy-scape elements in creating sustainable economic project in 
Egyptian parks. Ain Shams Engineering Journal, 9(4), pp. 3045-3053. DOI: https://doi.org/10.1016/j.asej.2018.09.00 1

[28] Rania Rushdy Moussa. (2019). The Reasons For Not Implementing Green Pyramid Rating System In Egyptian Buildings. Ain Shams Engineering Journal, 10(4); 917-927.
DOI: https://doi.org/10.1016/j.asej.2019.08.003

[29] Julianne Kinyingi, Njuguna Mugwima, and Dennis Karanja. (2020). Walkable Streets: A Study of Pedestrians' Perception, and Attitude towards Ngei Street in Machakos Town. Current Urban Studies. ISSN: 2328-4919. Vol. 8(3), pp. 381-395. DOI: https://doi.org/10.4236/cus.2020.83021. 